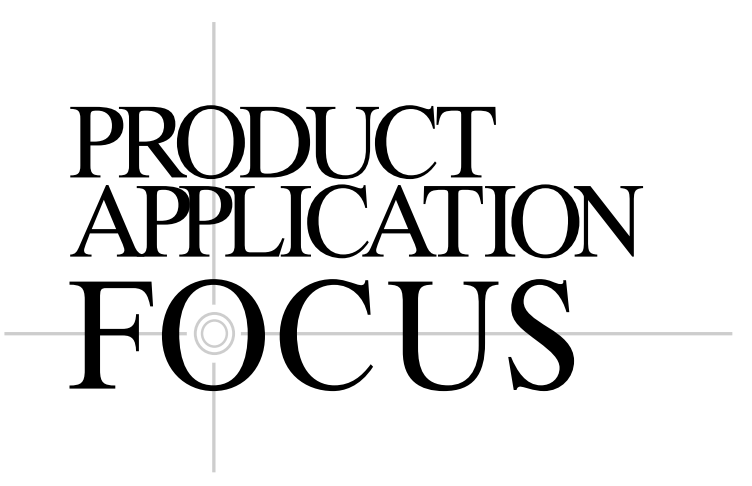

\author{
... a forum for manufacturers to describe the \\ current and potential applications of new \\ research instruments or products.
}

\title{
Fluorescence-Based, High-Throughput DNA Polymerase Assay
}

\author{
Liming Yu, Guolu Hu, and Leighton Howells
}

Amersham Biosciences, Piscataway, NJ, USA

BioTechniques 33:938-941 (October 2002)

\begin{abstract}
The commonly used DNA polymerase assay is based on the detection of incorporated radiolabeled nucleotides in a DNA elongation reaction. It is laborious, radioactive, and can be highly variable. Here we report a nonradioactive fluorescence-based assay. The method consists of Cydye ${ }^{T M}$-labeled nucleotides, biotinylated primer, and a streptavidin-coated microplate. The assay is found to have sensitivity and dynamic range comparable to the classical radioactive method. Moreover, it has the advantages of being simple, stable, nonradioactive, and suitable for high-throughput applications. We have also found that, to ensure efficient measurement of the enzyme activity, the template DNA used in this method should have a sequence that avoids the incorporation of the fluorescence-labeled nucleotide in a consecutive way.
\end{abstract}

\section{INTRODUCTION}

DNA polymerase activity measurement is a basic and fundamental assay that is extensively used in a variety of molecular biology investigations, such as the quantitative evaluation of cloned and recombinant DNA polymerases. Additionally, in drug discovery and disease diagnosis, DNA polymerase is an important target. Examples include infectious diseases, such as those caused by hepatitis B virus $(2,5)$, herpes simplex virus $(4,8)$, and Plasmodium falciparum (3). DNA polymerase is also a potential target for cancer therapy (6). However, the commonly used DNA polymerase assay (1), which has been a standard method for several decades, is based on the incorporation of radioisotope-labeled dNTP, acid precipitation, and filtration. It is subject to the laboratory constraints of radioisotope usage and disposal regulations. In addition, filtration assays are not suitable for high-throughput applications. A fluorometric assay utilizing a dsDNA-specific dye, PicoGreen ${ }^{\circledR}$, has been developed $(7,9)$. Here we describe an- other fluorescence-based method for the DNA polymerase activity assay. The system consists of a synthetic DNA template, a biotinylated primer, the fluorescence-labeled dCTP, and a streptavidin-coated microplate. Compared to the conventional filtration assay, the method is more convenient, faster, and allows measurements in parallel. Thus, it is suitable for applications requiring large-scale DNA polymerase measurement, such as high-throughput screening of DNA polymerase inhibitors in drug discovery.

\section{MATERIALS AND METHODS}

\section{Fluorescence DNA Polymerase Assay}

Enzyme reaction. Thermo Sequenase II DNA polymerase and Taq DNA polymerase (both from Amersham Biosciences, Piscataway, NJ, USA) were measured using the following conditions.

For Thermo Sequenase II ${ }^{\mathrm{TM}}$ DNA polymerase, $0.1-1.0 \mathrm{U}$ were used for each reaction. The reaction buffer contained 25 mM TAPS [tris-(hydroxymethyl)-methyl-amino-propanesulfonic acid, sodium salt, $\mathrm{pH}$ 9.3], $50 \mathrm{mM} \mathrm{KCl,} 2 \mathrm{mM} \mathrm{MgCl}_{2}, 1$ $\mathrm{mM}$ 2-mercaptoethanol. The reaction was performed in 0.6$\mathrm{mL}$ microcentrifuge tubes with a volume of $25 \mu \mathrm{L}$, which contained dGTP, dATP, dTTP, and Cy3-dCTP (Amersham Biosciences) each at $20 \mu \mathrm{M}$, template DNA $0.5 \mu \mathrm{g}$ (for plasmid) or at $1 \mu \mathrm{M}$ (for oligonucleotides), and $5^{\prime}$-biotinylated primer at $1 \mu \mathrm{M}$. The reaction temperature was $90^{\circ} \mathrm{C}$ for $5 \mathrm{~min}$, followed by $74^{\circ} \mathrm{C}$ for $10 \mathrm{~min}$. The temperature was reduced to $4^{\circ} \mathrm{C}$, and EDTA was added to a final concentration of $10 \mathrm{mM}$ to stop the reaction. Three different DNA templates have been tested (see Figure 3). They are FT1, a custom synthesized oligonucleotide, single-stranded M13 DNA, and the human p53 clone PUCp53 (Amersham Biosciences). For the templates FT1 and M13, a biotinylated M-13 Forward (-20) primer was used. For 
the human p53 template, a biotinylated primer derived from the p53 exon 5 was used. All oligonucleotides were custom synthesized by IDT (Coralville, IA, USA).

For Taq DNA polymerase, 0.1-1.0 U were used for each reaction. The reaction buffer contained $10 \mathrm{mM}$ Tris- $\mathrm{HCl}(\mathrm{pH}$ 8.6), $50 \mathrm{mM} \mathrm{KCl}, 1.5 \mathrm{mM} \mathrm{MgCl}_{2}$, and $0.1 \%$ Triton ${ }^{\circledR} \mathrm{X}-100$. The reaction volume, dGTP, dATP, dTTP, Cy3-dCTP, template DNA (FT1), primer (5'-biotinylated M-13 forward primer), reaction temperature, time, and termination were identical to the Thermo Sequenase II DNA polymerase reaction.

Capture of enzymatic product and measurement. A streptavidin-coated, 96-well black plate (BD Biosciences, San Jose, CA, USA) was pre-washed with $200 \mu \mathrm{L}$ wash buffer ( 25 $\mathrm{mM}$ Tris-HCl, pH 7.2, 0.05\% Tween ${ }^{\circledR} 20,150 \mathrm{mM} \mathrm{NaCl}$ ). Wash buffer $(30 \mu \mathrm{L})$ was added to the reaction mixtures. The reactions were transferred to the streptavidin-coated plate. The plate was incubated at room temperature for $30 \mathrm{~min}$ with intermittent shaking. The liquid was removed, and the wells were washed three times with $200 \mu \mathrm{L}$ wash buffer. Water (50 $\mu \mathrm{L}$ ) was added, and the plate was incubated at room temperature for $60 \mathrm{~min}$ with shaking. The plate was read in a fluorescence plate reader [(Farcyte ${ }^{\mathrm{TM}}$; Amersham Biosciences) or HTS7000 Plus ${ }^{\mathrm{TM}}$ (Perkin Elmer Life Sciences, Wellesley, MA, USA)] using the following conditions: manual gain 80 (Farcyte) or 180 (HTS7000 Plus); number of flashes, 3; integration time, $40 \mu \mathrm{s}$; excitation filter, $535 \mathrm{~nm}$; and emission filter, $595 \mathrm{~nm}$.

\section{DNA Polymerase Filtration Assay}

Enzyme reaction. The Taq and Thermo Sequenase II DNA polymerases were also assayed with the filtration method. The enzyme amount, reaction buffer, and conditions were similar to that of the fluorescence assay with the following changes: dNTPs were at $200 \mu \mathrm{M}$ each with $\alpha\left[{ }^{32} \mathrm{P}\right] \mathrm{dATP}$ $(0.05 \mathrm{Ci} / \mathrm{mmol}$; Amersham Biosciences) and activated salmon sperm DNA template at $20 \mu \mathrm{g} /$ reaction. The assay volume was $50 \mu \mathrm{L}$. The reaction was performed at $74^{\circ} \mathrm{C}$ for $10 \mathrm{~min}$ and was terminated by the addition of EDTA to $10 \mathrm{mM}$.
Filtration and measurement. One milliliter of $2 \mathrm{mM}$ EDTA containing $50 \mu \mathrm{g} / \mathrm{mL}$ sheared salmon sperm DNA was added to the reaction mixture. The DNA was precipitated by the addition of $1 \mathrm{~mL} \mathrm{20 \% (w/v)} \mathrm{trichloroacetic} \mathrm{acid} \mathrm{and} 2 \%$ $(\mathrm{w} / \mathrm{v})$ sodium pyrophosphate and then incubated at $0^{\circ} \mathrm{C}$ for at least $15 \mathrm{~min}$.

Precipitated DNA was collected on glass fiber filter discs (Enzo Diagnostics, Farmingdale, NY, USA) and washed extensively with a mixture of $1 \mathrm{M} \mathrm{HCl}$ and $100 \mathrm{nM}$ sodium pyrophosphate. The filter was placed into $3 \mathrm{~mL}$ aqueous scintillant and counted in a liquid scintillation counter.

\section{RESULTS AND DISCUSSION}

The thermostable Taq and Thermo Sequenase II are among the most commonly used DNA polymerases. The former is for PCR, and the latter is for automatic DNA sequencing. With the conventional radiometric filtration assay, which is routinely used in our institute for measuring the activities of a variety of DNA polymerases, the linear range of the two enzymes was found to be from 0.1 to $1.0 \mathrm{U} /$ reaction. We have compared the fluorescent assay and the filtration assay with the two enzymes within that range. To correlate the two assays better, aliquots of enzyme dilutions were divided into two portions. One portion was measured with the filtration assay and the other with fluorescent assay. The result showed that the two assays correlated each other quite well (Figure 1). Besides being nonradioactive, the protocol described here has the following additional advantages. The laborious filtration process in the old method is replaced by a simple plate-capturing step, and the time-consuming liquid scintillation counting, which typically takes about $1 \mathrm{~min} / \mathrm{sample}$, is now replaced by a quick fluorescence reading that takes less than $1 \mathrm{~s} / \mathrm{sample}$. With the new method, it is practical to do hundreds of thousands of assays in a reasonable period. Therefore, the fluorescence-based assay is extremely useful in applications such as the high-throughput screening of drugs targeting DNA polymerase or the large-scale screening of enzyme mutants.

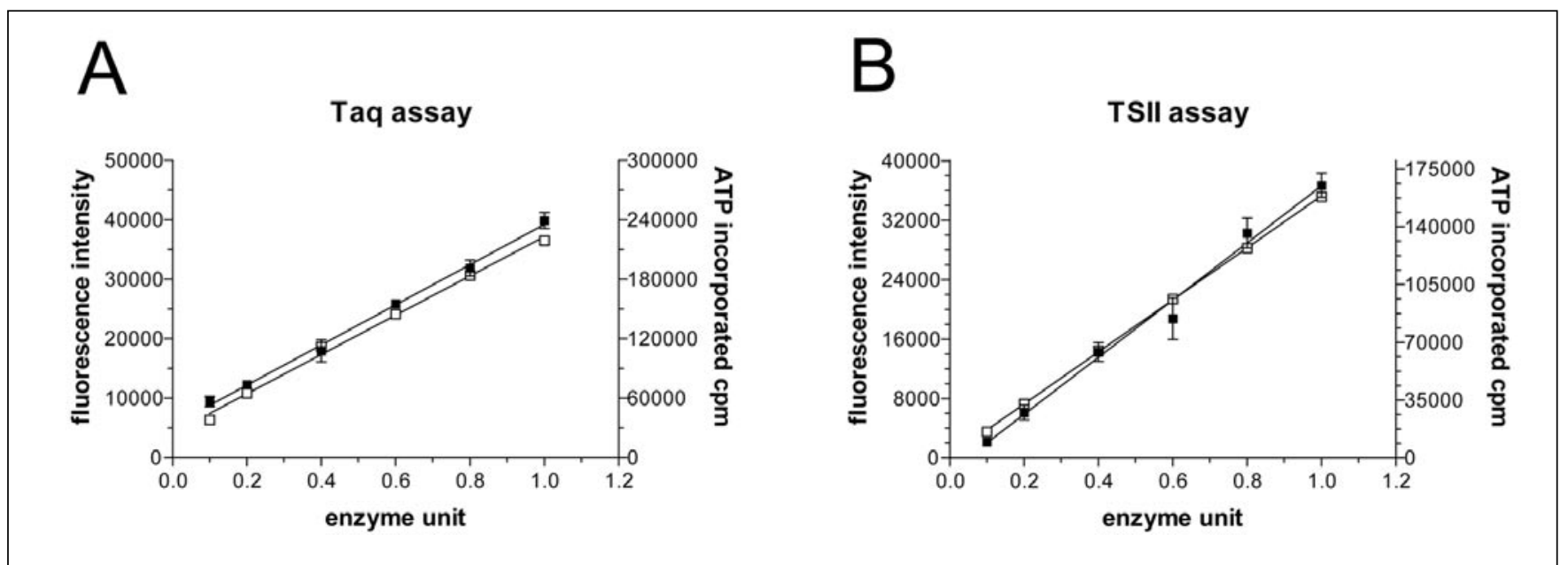

Figure 1. Comparison of fluorescence assay and filtration assay. Aliquots of DNA polymerase Taq (A) and Thermo Sequenase II (TSII) (B) dilutions were divided into two portions: one for the fluorescence assay $(\mathbf{\square})$ and the other for the traditional radiometric filtration assay $(\square)$. The enzymatic reaction conditions were described in the Materials and Methods. The template DNA for the fluorescence assay was FT1, a 63-mer synthetic oligonucleotide, and the primer was a biotinylated M-13 forward primer (F-20). The dCTP was fluorescence Cy3-labeled (FluoroLink ${ }^{\mathrm{TM}}$ Cy3-dCTP, PA 53021; Amersham Biosciences) along with the other three nonlabeled dNTPs. The extended DNA products were captured by a streptavidin-coated, 96-well black microplate. The results were analyzed in a Farcyte fluorescence plate reader. Each data point represents the mean of three replicates. 
The fluorescence labeling of dNTP may affect the DNA polymerase affinity; therefore, the absolute enzyme activity may be different from that obtained with the conventional assay. The fluorescence assay can be used to obtain a relative enzyme activity and to compare different enzymes. When absolute enzyme activity is needed, a standard enzyme should be included in the assay as a control.

It is surprising that the comparison of several templates has shown that only the FT1 is an effective template, while no or low enzymatic activity could be detected with the two randomly selected natural templates, M13 and p53 (Figure 2). PCR with these natural templates and non-fluorescence-labeled dCTP worked well, as demonstrated by DNA agarose electrophoresis analysis (data not shown). These results suggest that the low or no activity in the fluorescent assay must relate to the fluorescence-labeled dCTP. A difference between the designed template and the natural ones is that there are several "G" (the complementary residue to the Cy3-dCTP) clusters in the natural DNA templates downstream of the primer annealing sites, while there are no such clusters in the synthetic FT1 (Figure 3). DNA polymerases generally have a low affinity for the fluorescence labeled dNTP. Therefore, a lower consecutive incorporaion rate of fluorescence-labeled dNTPs would be expected. Another difference is that the Gs in the extension area of FT1 are all separated by nine nucleotides, while in the natural templates, some of them are close to each other, which may cause self-quenching by the integrated "Сy3-C". The nine-residue separation was theoretically selected and has been shown to be effective. However, a further investigation is necessary to determine the optimal distance. While the length of template FT1 is 63-mer, it is also interesting to determine whether the sensitivity and dynamic

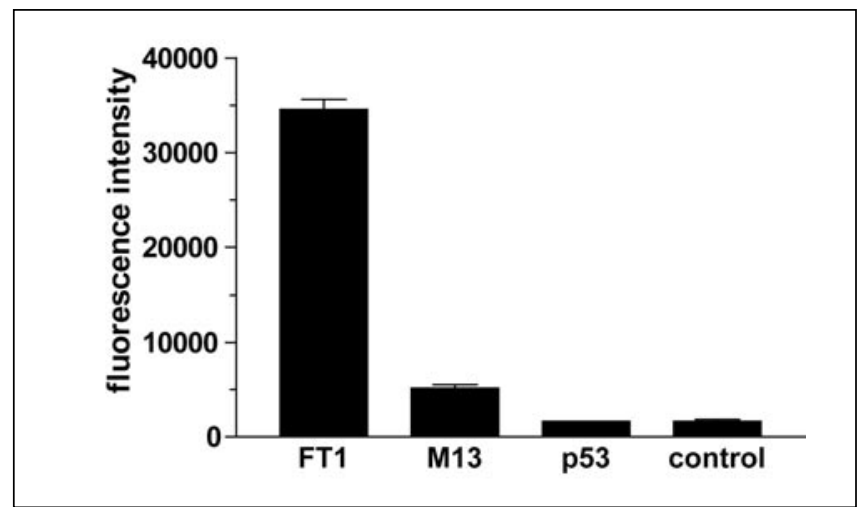

Figure 2. Templates study in fluorescent DNA polymerase assay. The assay conditions were the same as described in Figure 1. Three different templates were investigated: FT1, a 63-mer synthetic oligonucleotide; M13, a phage ssDNA; and $\mathrm{p} 53$, a fragment of cDNA derived from the human $p 53$ gene. The control had FT1 as the template but had no enzyme added. $\bar{x} \pm$ SD are $\operatorname{shown}(n=3)$.

\section{FT1 3' CAT TTT GCT GCC GGT CAC GTA AAA TTT TGT TAA ATA AAG AAT TTA TTA GTA... M13 (F -20) 5'biotin GTA AAA CGA CGG CCA GTG}

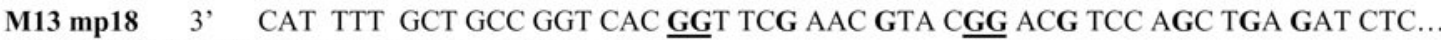 M13 (F -20) 5'biotin GTA AAA CGA CGG CCA GTG

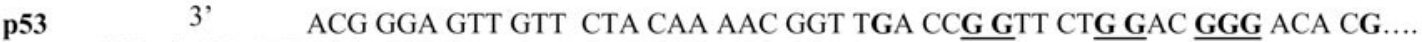 Bex5 5' biotin GAATT TGC CCT CAA CAA GAT GTT TTG CCA A}

Figure 3. The sequences of the templates and primers. The Gs in the extension region of template FT1 are separated from each other by nine nucleotides and indicated in bold. The clustered Gs in the templates M13mp18 and p53 are indicated by underlines. Only partial template sequences downstream of the primer annealing sites are shown here. The primers for FT1 and M13mp18 are the same, M13 Forwarding (F-20). Primer Bex5 was derived from human p53 exon 5. All the primers were biotinylated at $5^{\prime}$-end, as indicated by "biotin".

\section{Taq}

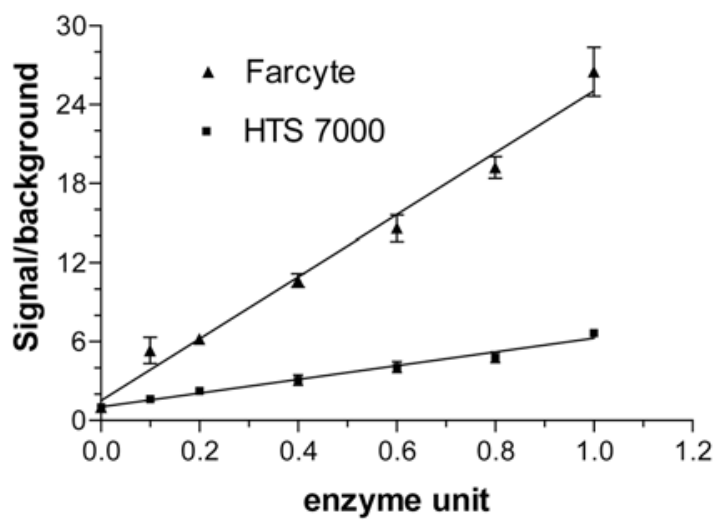

TSII

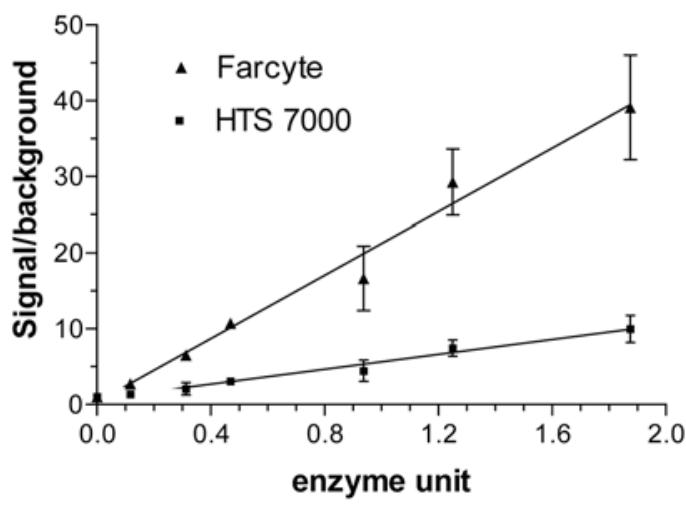

Figure 4. Comparison of fluorescence plate readers. The same samples were sequentially read in Farcyte and HTS7000 Plus. The measurement parameters used for the two instruments were identical: the number of flashes was 3; the integration time was $40 \mu \mathrm{s}$; the excitation filter was $535 \mathrm{~nm}$ and emission filter 595 $\mathrm{nm}$; and the gain was manual, 80 for Farcyte and 180 for HTS7000 Plus. The unit of the y-axis is the signal-to-noise ratio; the noise is the reading when the enzyme amount is zero. 
range of the assay can be further improved by using a template of different length.

Figure 4 shows the results obtained with two different fluorescence plate readers, the Farcyte and the HTS7000 Plus. The same samples were measured sequentially in the two instruments and compared side by side. The data obtained with Farcyte shows a higher signal-to-noise ratio. It is thought that the ability for Farcyte to adjust $\mathrm{Z}$ position (focus) might contribute in the superior performance. The result indicates that an optimized fluorescence plate reader will increase substantially the sensitivity of the DNA polymerase fluorescence assay.

The trend for assays in drug discovery screening is nonradioactive and higher throughput. The method described here meets these criteria. Nevertheless, the finding that a specially designed or selected template would facilitate the assay is a surprise. This may explain why there is no report so far on the DNA polymerase assay with fluorescence-labeled dNTPs. Based on the same principle, the assay can be easily adapted to measuring other nucleic acid polymerases, such as the RNA polymerase and reverse transcriptase, with a well-designed template.

\section{ACKNOWLEDGMENTS}

The authors thank Dr. Carl Fuller and Mr. Haiguang Xiao of Amersham Bioscience for constructive discussion regarding the non-cluster DNA template.

\section{REFERENCES}

1.Aposhian, H.V. and A. Kornberg. 1962. Enzymatic synthesis of deoxyribonucleic acid. J. Biol. Chem. 237:519-525.

2.Cappel, R., F. De Cuyper, D. Van Beers, M. Toppet, and S. Cadranel. 1977. Early diagnosis of hepatitis B by dane particle associated DNA polymerase assay. J. Gen. Virol. 36:217-220.

3.De Vries, E., J.G. Stam, F.F. Franssen, and H. Nieuwenhuijs. 1991. Inhibition of the growth of Plasmodium falciparum and Plasmodium berghei by the DNA polymerase inhibitor HPMPA. Mol. Biochem. Parasitol. 47:43-50.

4.Digard, P., K.P. Williams, P. Hensley, I.S. Brooks, C.E. Dahl, and D.M. Coen. 1995. Specific inhibition of herpes simplex virus DNA polymerase by helical peptides corresponding to the subunit interface. Proc. Natl. Acad. Sci. USA 28:1456-1460.

5.Hernandez, A., F.J. Belda, J. Dominguez, L. Matas, M. Gimenez, M. Caraballo, C. Ramil, and V. Ausina. 1997. Inactivation of hepatitis B virus: evaluation of the efficacy of the disinfectant "Solprogel" using a DNA-polymerase activity assay. J. Hosp. Infect. 36:305-312.

6.Kelley, T.J., S. Moghaddas, R. Bose, and S. Basu. 1993. Inhibition of immunopurified DNA polymerase-alpha from PA-3 prostate tumor cells by platinum (II) antitumor drugs. Cancer Biochem. Biophys. 13:135-146.

7.Seville, M., A.B. West, M.G. Cull, and C.S. McHenry. 1996. Fluorometric assay for DNA polymerases and reverse transcriptase. BioTechniques 21:664-672.

8.Terry, B.J., W.C. Liu, C.W. Cianci, E. Proszynski, P. Fernandes, K. Bush, and E. Meyers. 1992. Inhibition of herpes simplex virus type 1 DNA polymerase by the natural product oosporein. J. Antibiot. 45:286-288.

9.Tveit, H. and T. Kristensen. 2000. Fluorescence-based DNA polymerase assay. Anal. Biochem. 289:96-98.

Address correspondence to Dr. Liming Yu, Amersham Biosciences, R\&D, 800 Centennial Ave., Piscataway, NJ 08855, USA.e-mail: liming.yu@am.amershambiosciences.com 